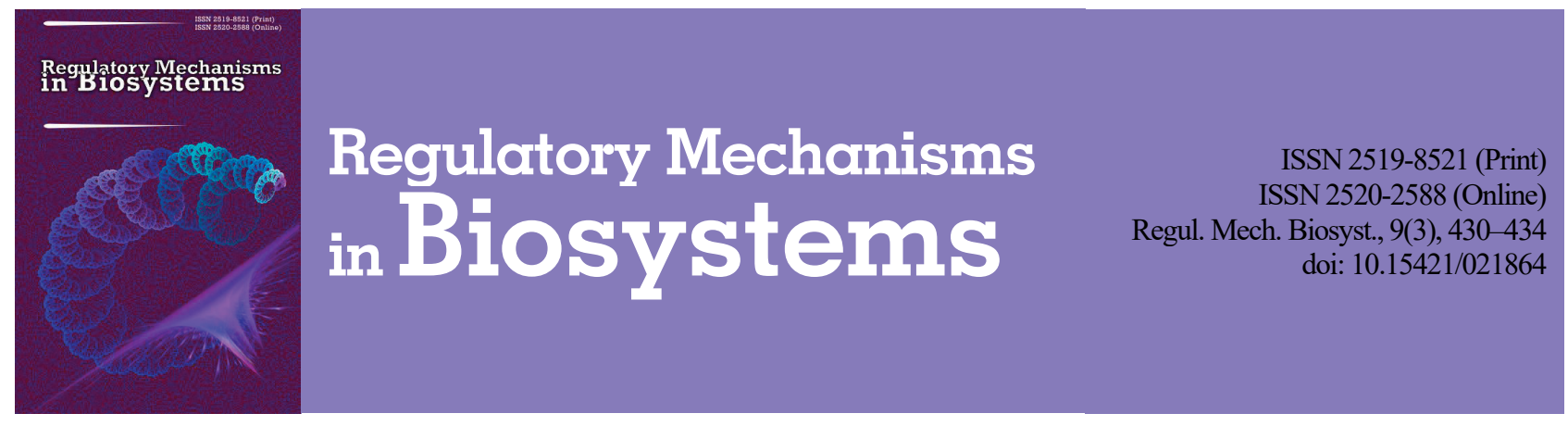

\title{
Optimization of the 9a-hydroxylation of steroid substrates using an original culture of Rhodococcus erythropolis
}

\author{
V. A. Andryushina, N. V. Karpova, T. S. Stytsenko, V. V. Yaderets, E. D. Voskresenskaya, V. V. Dzhavakhia \\ Federal Research Center "Fundamentals of Biotechnology”, Russian Academy of Sciences, Moscow, Russian Federation
}

Article info

Received 07.06.2018

Received in revised form

12.07.2018

Accepted 16.07.2018

Federal Research Center "Fundamentals of

Biotechnology", Russian

Academy of Sciences,

Leninsky prospect, 33/2

Moscow, 119071

Russian Federation.

Tel.: +7-499-135-30-49.

E-mail:

andryushina@rambler.ru

\begin{abstract}
Andryushina, V. A., Karpova, N. V., Stytsenko, T. S., Yaderets, V. V., Voskresenskaya, E. D., \& Dzhavakhia, V. V. (2018). Optimization of the $9 \alpha$-hydroxylation of steroid substrates using an original culture of Rhodococcus erythropolis. Regulatory Mechanisms in Biosystems, 9(3), 430-434. doi:10.15421/021864
\end{abstract}

To obtain inoculation material (cultivation stage 1), the biomass of Rhodococcus erythropolis VKPM AC-1740 was transferred from agar slants into $750 \mathrm{ml}$ conic flasks containing $100 \mathrm{ml}$ of vegetation media of the following composition $(\mathrm{g} / \mathrm{l})$ : medium 1 - yeast extract, 10.0; glucose, 10.0; soybean flour, 10.0; $\mathrm{KH}_{2} \mathrm{PO}_{4}, 2.0 ; \mathrm{Na}_{2} \mathrm{HPO}_{4}, 4.0$ (pH 6.8-7.4); medium 2 - corn extract, 15.0; glucose, 10.0; $\mathrm{KH}_{2} \mathrm{PO}_{4}, 2.0 ; \mathrm{Na}_{2} \mathrm{HPO}_{4}, 4.0(\mathrm{pH} 6.8-7.4)$. The culture was grown on a rotary shaker $(220 \mathrm{rpm})$ for $68-72 \mathrm{~h}$ at $28-29^{\circ} \mathrm{C}$. To obtain a working biomass (cultivation stage 2), the inoculum obtained at the stage 1 was transferred into flasks containing the same media (the volume of seed material was $20 \%$ of the medium volume) and grown under the same conditions for $23-25 \mathrm{~h}$. During a study of the effect of the inducer concentration on the rate of $9 \alpha-\mathrm{OH}-\mathrm{AD}$ formation, different concentrations $(0.25,0.50$, and $1 \mathrm{~g} / \mathrm{l})$ of the $\mathrm{AD}$ solution in dimethylformamide (DMF) were added to the vegetation medium after $6 \mathrm{~h}$ of incubation. To perform $\mathrm{AD}$ transformation at a load of $5 \mathrm{~g} / \mathrm{l}, 10 \mathrm{ml}$ of Rh. erythropolis cells at the age of $23-25 \mathrm{~h}$ were transferred into $750 \mathrm{~mL}$ flasks with baffles containing $40 \mathrm{~mL}$ of vegetation medium supplemented with the steroid. $\mathrm{AD}$ was added in the form of microcrystals or suspension with a surfactant or DMF. The process was carried out at $28-29^{\circ} \mathrm{C}$ and with constant mixing (220 rpm). During AD transformation at a load of $10-30 \mathrm{~g} / \mathrm{l}$, the steroid was preliminarily precipitated from DMF solution. The resulting paste was mixed with a surfactant and transformation medium. The obtained homogeneous suspension was poured in equal amounts into the flasks with baffles, and then a concentrated cell mass was added $(25 \mathrm{vol} . \%)$. To obtain a cell concentrate, cells were centrifuged for $1 \mathrm{~h}$ at $1500 \mathrm{rpm}$ at the age of $23-25 \mathrm{~h}$. The resulting biomass was homogenized, supplemented with a fresh medium to the required volume, and added into transformation flasks. The amount of a biomass required for $\mathrm{AD}$ transformation at a load of $10 \mathrm{~g} / 1$ was $3.13 \mathrm{~g} / 1$ (dry weight); in the case of a $30 \mathrm{~g} / 1$ load, the biomass was added by two equal portions, and its total amount was $6.2 \mathrm{~g} / \mathrm{l}$ (dry weight). The amount of $9 \alpha-\mathrm{OH}-\mathrm{AD}$ in a culture broth was evaluated by a thin-layer chromatography (TLC) and high-performance liquid chromatography (HPLC). Steroids were extracted by ethylacetate. To perform TLC, Sorbifil plates (Russia) and benzol: acetone mix $(3: 1)$ were used. HPLC was performed on a Gilson chromatographer (United States) equipped with a Silasorb C-18 column $(10 \mu \mathrm{m}, 4.0 \times 250 \mathrm{~mm}$ ); the flow rate was $0.8 \mathrm{ml} / \mathrm{min}$. The mobile phase was $\mathrm{MeOH}: \mathrm{H}_{2} \mathrm{O}$ mix $(70: 30)$. The absorbance was measured at $260 \mathrm{~nm}$. Replacement of corn extract, which has an unstable composition, by yeast extract and soybean flour and the use of glucose as an optimal carbon source for a Rh. erythropolis culture have provided a high-yield production of $9 \alpha$-hydroxy-4-ene-3,17-dione with increased AD loads. Use of such techniques as the inoculum induction and application of surfactants have provided a positive effect on the $\mathrm{AD}$ transformation with a load exceeding $10 \mathrm{~g} / \mathrm{l}$. During $9 \alpha$-hydroxylation of AD with a load of $30 \mathrm{~g} /$, a target product with the yield of $83 \%$ has been obtained.

Keywords: fluorinated corticoids; AD; 9 $\alpha-\mathrm{OH}-\mathrm{AD}$; Rhodococcus erythropolis VKPM AC-1740; surfactants; inducer.

\section{Introduction}

Deterioration of environmental conditions and the corresponding increase in the number of allergic and inflammatory diseases on the global scale gives rise to a growing need for steroid preparations of different therapeutic action. According to analytic forecasts, the volume of the steroid market in 2021 will reach 4.480 million US dollars (FernandezCabezon et al., 2018; Barredo \& Herráiz, 2017, Fernandes et al., 2003). Thus, despite the existing achievements in the biotechnology of steroid production, the development of effective methods of synthesis of androgenic, gestagenic, mineral, and glucocorticoid steroid preparations from natural plant products still remains relevant (Brzezinska et al., 2013; Guevara et al., 2017a; Fernandez-Cabezon et al., 2018).

The main indications for glucocorticosteroid therapy of humans include rheumatoid arthritis, bronchial asthma, neurodermatitis and other skin and allergic diseases, acute adrenal insufficiency, and also various shock states (post-rheumatic, operational, toxic, burn, etc.). Today the most common anti-inflammatory steroids represent structural modifications of natural compounds and are characterized by improved therapeutic properties and weaker side effects. Among such preparations, fluorinated corticosteroids (dexamethasone, sinaflan, triamcinolone, fluticasone, etc.) are in the greatest demand (Mashkovskiy, 2012).

$9 \alpha$-hydroxy-4-ene-3,17-dione ( $9 \alpha-\mathrm{OH}-\mathrm{AD})$ is the basic intermediate in the synthesis of the aforementioned drug preparations from sterols (Fernández de las Heras et al., 2012; Mohn et al., 2012; Jakočiunas et al., 2016; Mondaca et al., 2017). According to the existing data, $9 \alpha$-hydroxylation, which represents a key reaction in the synthesis of fluorinated corticoids, cannot be realized via chemical synthesis (Guevara et al., 2017). Therefore, a cost-efficient large-scale production of this class of drugs is possible only with the use of microorganisms able to perform a highly selective targeted transformation of steroid molecules of a given structure under ecologically safe conditions and without any need for preliminary protection of the functional groups of the initial molecule (Mutafova et al., 2016; Smitha et al., 2017). 
It is known that some lower fungi (Ascochyta, Helicostilum, Circinella) and many bacteria, especially actinobacteria (Arthrobacter, Corynebacterium, Mycobacterium, Nocardia, Rhodococcus) are able to introduce $9 \alpha$-hydroxygroups into a steroid molecule. However, steroid hydroxylation with fungi does not provide a sufficient selectivity of the process. Along with the formation of a target hydroxysteroid, fungi also produce a number of side mono- and dihydroxy-products, which complicates the further isolation of the target product and significantly reduces its yield. In addition, both position and orientation of an introduced hydroxyl group strongly depends on the structure of the steroid molecule (Donova \& Egorova, 2012; Andryushina et al., 2013; Barredo \& Herráiz, 2017)

Unlike fungi, bacteria perform $9 \alpha$-hydroxylation reaction regardless of the steroid structure and presence of additional bonds and substituents. Therefore, actinobacteria capable of providing a high-selective introduction of a hydroxy group at the $9 \alpha$-position of a steroid molecule may be considered as the most promising bioreagents, since the corresponding bacterial enzyme shows the lower substrate specificity than steroid $9 \alpha$-monooxygenase of a fungal origin (Petrusma et al., 2009, 2011; Lee et al., 2016; Nielsen \& Keasling, 2016). However, $9 \alpha$-hydroxylation activity was detected only in bacteria which were able to use steroids as a carbon source since this reaction represents an intermediate stage of a complete cleavage of steroid molecules to $\mathrm{CO}_{2}$ and $\mathrm{H}_{2} \mathrm{O}$, at which the simultaneous action of 3-ketosteroid-1,2-dehydrogenase and 9 $\alpha$-hydroxylase is observed (Petrusma et al., 2014; Donova \& Egorova, 2012; Rodina et al., 2009). The analysis of published data showed that the selective $9 \alpha$-hydroxylation without any destruction of a steroid nucleus can be performed using bacterial strains carrying mutations, which block the biosynthesis of 1,2-dehydrogenase or prevent the functioning of this enzyme. In our previous study, we obtained a highly-selective Rhodococcus erythropolis strain VKPM AC-1740 with improved $9 \alpha$-hydroxylating activity (Rodina et al., 2009; Carpova-Rodina et al., 2011). Using this strain, we developed efficient technologies for the production of $9 \alpha$-hydroxy-steroid derivatives (Vojshvillo et al., 2007) and developed several efficient methods for $9 \alpha-\mathrm{OH}-\mathrm{AD}$ production from sterols including the mixed culture method (Andryushina et al., 2011) or the use of original biocatalyst representing $R$. erythropolis VKPM AC-1740 cells immobilized in a PVA cryogel (Carpova-Rodina et al., 2011).

A common disadvantage of all methods for $9 \alpha$-hydroxylation of steroids, which were previously developed by our team, was the dependence of the hydroxylating activity of $R$. erythropolis VKPM AC-1740 on a nutrient medium composition, namely, the quality of the corn extract used as the main nitrogen source (Ribeiro et al., 2017; van der Geize et al., 2001, 2001, 2008). The composition of a corn extract is determined by several factors, such as the grain quality, scheme and mode of its soaking, and the extract thickening procedure. Corn extract may contain some impurities, which provide a negative effect on microorganisms and reduce their enzymatic activity. Because of fluctuations in the activity of a culture grown on such medium, there is a need to select an alternative nitrogen source with the further optimization of the hydroxylation process under new fermentation conditions. At this stage of our work, yeast extract was chosen as a stable and available source of organic nitrogen.

Thus, the aim of this study was to evaluate the $9 \alpha$-hydroxylating activity of $R$. erythropolis VKPM AC-1740, grown on media containning yeast extract and soybean flour as the main nitrogen sources, in relation to the production of $9 \alpha-\mathrm{OH}-\mathrm{AD}$ from $\mathrm{AD}$ at the initial $\mathrm{AD}$ concentration equal to $10-30 \mathrm{~g} / \mathrm{l}$.

\section{Materials and Methods}

Strain, nutrient media and cultivation conditions. The earlier developed R. erythropolis VKPM AC-1740 strain characterized by a high $9 \alpha$-hydroxylating activity in relation to $\Delta 4-3$-ketosteroids, was used in the study. The culture was stored on solid agar medium of the following composition (g/l): yeast extract, 10.0; glucose, $10.0 ; \mathrm{KH}_{2} \mathrm{PO}_{4}, 1.0(\mathrm{pH}$ 6.8-7.2). To obtain inoculation material (cultivation stage 1), the biomass of $R$. erythropolis was transferred from agar slants into $750 \mathrm{ml}$ conic flasks containing $100 \mathrm{ml}$ of vegetation media of the following composition (g/l): medium 1 - yeast extract, 10.0; glucose, 10.0; soy- bean flour, 10.0; $\mathrm{KH}_{2} \mathrm{PO}_{4}, 2.0 ; \mathrm{Na}_{2} \mathrm{HPO}_{4}, 4.0$ (pH 6.8-7.4); medium 2 corn extract, 15.0; glucose, 10.0; $\mathrm{KH}_{2} \mathrm{PO}_{4}, 2.0 ; \mathrm{Na}_{2} \mathrm{HPO}_{4}, 4.0(\mathrm{pH} 6.8$ 7.4). The culture was grown on a rotary shaker $(220 \mathrm{rpm})$ for $68-72 \mathrm{~h}$ at $28-29^{\circ} \mathrm{C}$.

To obtain a working biomass (cultivation stage 2), the inoculum obtained at the stage 1 was transferred into flasks containing the same media (the volume of seed material was $20 \%$ of the medium volume) and grown under the same conditions for 23-25 h. During the study of the effect of the inducer concentration on the rate of $9 \alpha-\mathrm{OH}-\mathrm{AD}$ formation, different concentrations $(0.25,0.50$, and $1 \mathrm{~g} / \mathrm{l})$ of the $\mathrm{AD}$ solution in dimethylformamide (DMF) were added to the vegetation medium after $6 \mathrm{~h}$ of incubation.

Biotransformation conditions. To perform $\mathrm{AD}$ transformation at a load of $5 \mathrm{~g} / \mathrm{l}, 10 \mathrm{ml}$ of $R$. erythropolis cells at the age of $23-25 \mathrm{~h}$ were transferred into $750 \mathrm{ml}$ flasks with baffles containing $40 \mathrm{ml}$ of vegetation medium supplemented with the steroid. $\mathrm{AD}$ was added in the form of microcrystals or suspension with a surfactant or DMF. The process was carried out at $28-29^{\circ} \mathrm{C}$ and a constant mixing $(220 \mathrm{rpm})$.

During AD transformation at a load of 10-30 $\mathrm{g} / \mathrm{l}$, the steroid was preliminarily precipitated from the DMF solution. The resulting paste was mixed with a surfactant and transformation medium. The obtained homogeneous suspension was poured in equal amounts into the flasks with baffles, and then a concentrated cell mass was added ( 25 vol. \%).

To obtain a cell concentrate, cells were centrifuged for $1 \mathrm{~h}$ at $1500 \mathrm{rpm}$ at the age of 23-25 h. The resulting biomass was homogenized, supplemented with a fresh medium to the required volume, and added into transformation flasks. The amount of a biomass required for $\mathrm{AD}$ transformation at a load of $10 \mathrm{~g} / \mathrm{l}$ was $3.13 \mathrm{~g} / \mathrm{l}$ (dry weight); in the case of a $30 \mathrm{~g} / 1$ load, the biomass was added by two equal portions, and its total amount was $6.2 \mathrm{~g} / \mathrm{l}$ (dry weight).

Transformation efficiency assessment. The amount of $9 \alpha-\mathrm{OH}-\mathrm{AD}$ in a culture broth was evaluated by a thin-layer chromatography (TLC) and high-performance liquid chromatography (HPLC). Steroids were extracted by ethylacetate. To perform TLC, Sorbifil plates (Russia) and benzol: acetone mix $(3: 1)$ were used. HPLC was performed on a Gilson chromatographer (United States) equipped with a Silasorb C-18 column $(10 \mu \mathrm{m}, 4.0 \times 250 \mathrm{~mm})$; the flow rate was $0.8 \mathrm{ml} / \mathrm{min}$. The mobile phase was $\mathrm{MeOH}: \mathrm{H}_{2} \mathrm{O}$ mix $(70: 30)$. The absorbance was measured at $260 \mathrm{~nm}$.

\section{Results}

Selection of Nitrogen and Carbon Sources. At the first stage of a nutrient medium optimization, a comparative $9 \alpha$-hydroxylation of $\mathrm{AD}$ with a $5 \mathrm{~g} / \mathrm{l}$ load was carried out using media 1 and 2 . The obtained results were identical for both media: a complete conversion of the initial compound with the formation of 4.7-4.8 g/l of $9 \alpha-\mathrm{OH}-\mathrm{AD}$ occurred within 20-22 h. Replacement of a carbon source in the medium 1 provided a more significant impact on the AD biotransformation process (Table 1). According to the obtained data, the best result was obtained using a modified medium containing soybean flour, yeast extract, and glucose. After $21 \mathrm{~h}$ of the $\mathrm{AD}$ transformation $(5 \mathrm{~g} / \mathrm{l}$ load $)$ in a modified medium, almost complete substrate conversion was observed with the formation of $9 \alpha-\mathrm{OH}-\mathrm{AD}$ as an individual compound. Therefore, this medium was chosen as the basic one for the further optimization of the conversion process.

Table 1

Effect of various carbon sources on the production of $9 \alpha-\mathrm{OH}-\mathrm{AD}$ by Rhodococcus erythropolis VKPM AC- 1740

\begin{tabular}{lcc}
\hline \multirow{2}{*}{$\begin{array}{c}\text { Carbon source } \\
(5 \mathrm{~g} / \mathrm{L})\end{array}$} & \multicolumn{2}{c}{ Average steroid content in a culture broth, $\%$} \\
\cline { 2 - 3 } & $9 \alpha-\mathrm{OH}-\mathrm{AD}$ & \multicolumn{1}{c}{$\mathrm{AD}$} \\
\hline Control (no carbon source) & $68 \pm 1.5$ & $30 \pm 1.5$ \\
Glucose & $98 \pm 1.0$ & $2 \pm 1.0$ \\
Fructose & $15 \pm 1.3$ & $84 \pm 1.3$ \\
Sucrose & $40 \pm 0.8$ & $60 \pm 0.8$ \\
Lactose & $12 \pm 1.5$ & $85 \pm 1.5$ \\
\hline
\end{tabular}

Note: hereinafter, the experimental error $( \pm)$ was determined as a random error of direct measurements using the following formula: $\Delta x=\left(x_{\max }-x_{\min }\right) / 2$, where $\mathrm{x}_{\max }$ и $\mathrm{x}_{\min }$ are the maximum and minimum values obtained by the series of repeated measurements. 
Effect of the AD introduction method on the $9 \alpha-O H-A D$ output. As we have mentioned earlier, one of the main problems of microbiological transformations of steroid substrates is the high hydrophobic property of steroid molecules; the solubility of steroids belonging to the androstane group does not exceed $20 \mathrm{mg} /$ (Goetschel \& Bar, 1992). To solve this problem, we added $\mathrm{AD}$ into a medium either in the form of a fine-dispersed suspension with various surfactants, or dissolved in DMF (Table 2).

Table 2

Effect of various surfactants on the production of $9 \alpha-\mathrm{OH}-\mathrm{AD}$ by Rhodococcus erythropolis VKPM AC-1740

\begin{tabular}{lcc}
\hline \multicolumn{1}{c}{$\begin{array}{c}\text { Surfactant used for } \\
\text { introduction of ground AD } \\
\text { into fermentation medium }\end{array}$} & \multicolumn{2}{c}{$\begin{array}{c}\text { Average steroid content } \\
\text { in a culture broth (TLC), \% }\end{array}$} \\
\cline { 2 - 3 } Tween 21* & $9 \alpha$-OH-AD & \multicolumn{1}{c}{ AD } \\
Tween 40 & $97 \pm 1.5$ & $3 \pm 1.5$ \\
Tween 61 & $96 \pm 1.3$ & $4 \pm 1.3$ \\
Tween 80 & $96 \pm 1.4$ & $4 \pm 1.4$ \\
Triton 100 & $99 \pm 0.3$ & $1 \pm 0.3$ \\
Span 20 & $95 \pm 1.6$ & $5 \pm 1.6$ \\
Span 80 & $98 \pm 1.3$ & $2 \pm 1.3$ \\
Emulan EL & $97 \pm 1.5$ & $3 \pm 1.5$ \\
DMF** & $90 \pm 1.3$ & $10 \pm 1.3$ \\
Control & $95 \pm 1.3$ & $5 \pm 1.3$ \\
\hline
\end{tabular}

Note: *-surfactant : AD ratio is $1: 4 ;{ }^{* *}$ - DMF 4 vol.\%.

According to the obtained results, the most efficient $\mathrm{AD}$ transformation at a $5 \mathrm{~g} / \mathrm{l}$ load was observed in the variant with Tween 80 . However, the control variant (i.e., without addition of any surfactant or solvent) demonstrated a quite comparable result.

Effect of the Inducer on a Microbiological $9 \alpha$-Hydroxylation by $R$. erythropolis VKPM AC-1740. 3-Ketosteroid-9 $\alpha$-hydroxylase (9-KSH) is a two-component non-heme iron-dependent Rieske monooxygenase consisting of a KshA oxygenase and a KshB reductase. 9-KSH is one of the key enzymes involved into a microbiological degradation of steroids and is of a great physiological importance for a wide range of steroid-transforming bacteria (Petrusma et al., 2014). The presence of a 3-keto group and also $\Delta 1$ and / or $\Delta 4$-double bonds in the $\mathrm{A}$ ring of the steroid nucleus is a necessary condition for a $9 \alpha$-hydroxylase activity (Akhrem \& Titov, 1970).

To study the stimulation of a 9-KSH biosynthesis, the inoculum of R. erythropolis VKPM AC-1740 was grown on a medium supplemented with $\mathrm{AD}$ as an inducer $(0.25,0.50$, and $1.0 \mathrm{~g} / \mathrm{l})$. The $\mathrm{AD}$ solution was added 6-7 h after inoculation by a second-generation culture. The total time of incubation was 23-25 h. The amount of the inoculum used for transformation of $\mathrm{AD}(5 \mathrm{~g} / \mathrm{l})$ was $20 \%$ of the medium volume. The result of the experiment is shown in Table 3.

Table 3

Consumption of $\mathrm{AD}(5 \mathrm{~g} / \mathrm{l})$ and accumulation of $9 \alpha-\mathrm{OH}-\mathrm{AD}$ by $R$. erythropolis VKPM AC-1740 grown in the presence of various concentrations of the inducer

\begin{tabular}{|c|c|c|c|c|c|c|c|c|}
\hline \multirow{4}{*}{ Time, } & \multicolumn{8}{|c|}{ Average steroid content in a culture broth, \% } \\
\hline & \multirow{2}{*}{\multicolumn{2}{|c|}{ control }} & \multicolumn{6}{|c|}{ inducer concentration, g/L } \\
\hline & & & \multicolumn{2}{|c|}{0.25} & \multicolumn{2}{|c|}{0.50} & \multicolumn{2}{|c|}{1.00} \\
\hline & $\mathrm{AD}$ & $\begin{array}{c}9 \alpha-\mathrm{OH}- \\
\mathrm{AD}\end{array}$ & $\mathrm{AD}$ & $\begin{array}{c}9 \alpha-\mathrm{OH}- \\
\mathrm{AD}\end{array}$ & $\mathrm{AD}$ & $\begin{array}{c}9 \alpha-\mathrm{OH}- \\
\mathrm{AD}\end{array}$ & АД & $\begin{array}{c}9 \alpha-\mathrm{OH}- \\
\mathrm{AD}\end{array}$ \\
\hline 0 & 5.0 & - & 5.0 & - & 5.0 & - & 5.0 & - \\
\hline 2 & 5.0 & - & 4.9 & 0.1 & 4.8 & 0.1 & 4.7 & 0.2 \\
\hline 4 & 5.0 & - & 4.7 & 0.2 & 4.6 & 0.2 & 4.5 & 0.3 \\
\hline 6 & 4.8 & 0.1 & 4.4 & 0.3 & 4.4 & 0.3 & 4.3 & 0.4 \\
\hline 12 & 1.9 & 2.9 & 1.5 & 3.2 & 1.3 & 3.4 & 1.2 & 3.3 \\
\hline 14 & 1.4 & 3.5 & 0.9 & 3.1 & 0.9 & 3.3 & 0.8 & 3.0 \\
\hline 16 & 1.0 & 3.9 & 0.4 & 3.0 & 0.3 & 3.1 & 0.2 & 2.9 \\
\hline 18 & 0.6 & 4.3 & - & 2.5 & - & 2.6 & - & 2.5 \\
\hline 20 & 0.1 & 4.7 & - & 2.1 & - & 2.4 & - & 2.0 \\
\hline
\end{tabular}

The $9 \alpha$-hydroxylating activity of $R$. erythropolis VKPM AC-1740 in the presence of the inducer was observed already after $2 \mathrm{~h}$ of transformation, whereas in the control variant it was registered only after 6 hours of transformation. For all variants with induced seed material, we observed an active destruction of the target product during transformation. A pro- bable explanation is that the induction of a 9-KSH biosynthesis may result in the induction of 1,2-dehydrogenase, responsible for the next reaction in the steroid nucleus degradation pathway.

Results obtained in this experiment were used for the study of the $A D$ transformation at a load of $10-30 \mathrm{~g} / \mathrm{AD}$ transformation into $9 \alpha-$ $\mathrm{OH}-\mathrm{AD}$ at a substrate load of $10 \mathrm{~g} / \mathrm{l}$. The effect of induction on the $\mathrm{AD}$ transformation at a load of $10 \mathrm{~g} / \mathrm{l}$ was examined using a concentrated R. erythropolis VKPM AC-1740 biomass (3.13 g/l of dry weight). The transformation time was $19-20 \mathrm{~h}$. The yield of $9 \alpha-\mathrm{OH}-\mathrm{AD}$ equal to 94.3\% and $94.0 \%$ (as determined by HPLC) was obtained in the case of the inducer concentration equal to $0.5 \mathrm{~g} / \mathrm{l}$; this yield exceeded that of the control by $10 \%$ (Fig. 1). A slight destruction of the target product was observed at the inducer concentration equal to $1.0 \mathrm{~g} / \mathrm{l}$ (Figs. 1, 2).

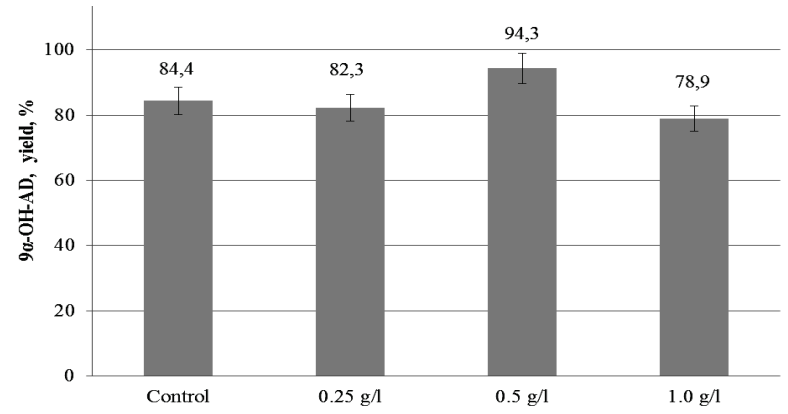

Fig. 1. Effect of various inducer concentrations on the yield of $9 \alpha-\mathrm{OH}-\mathrm{AD}$ at the end of the AD transformation by Rhodococcus erythropolis VKPM AC-1740: for all variants, the $\mathrm{AD}$ concentration was $10 \mathrm{~g} / \mathrm{l}$

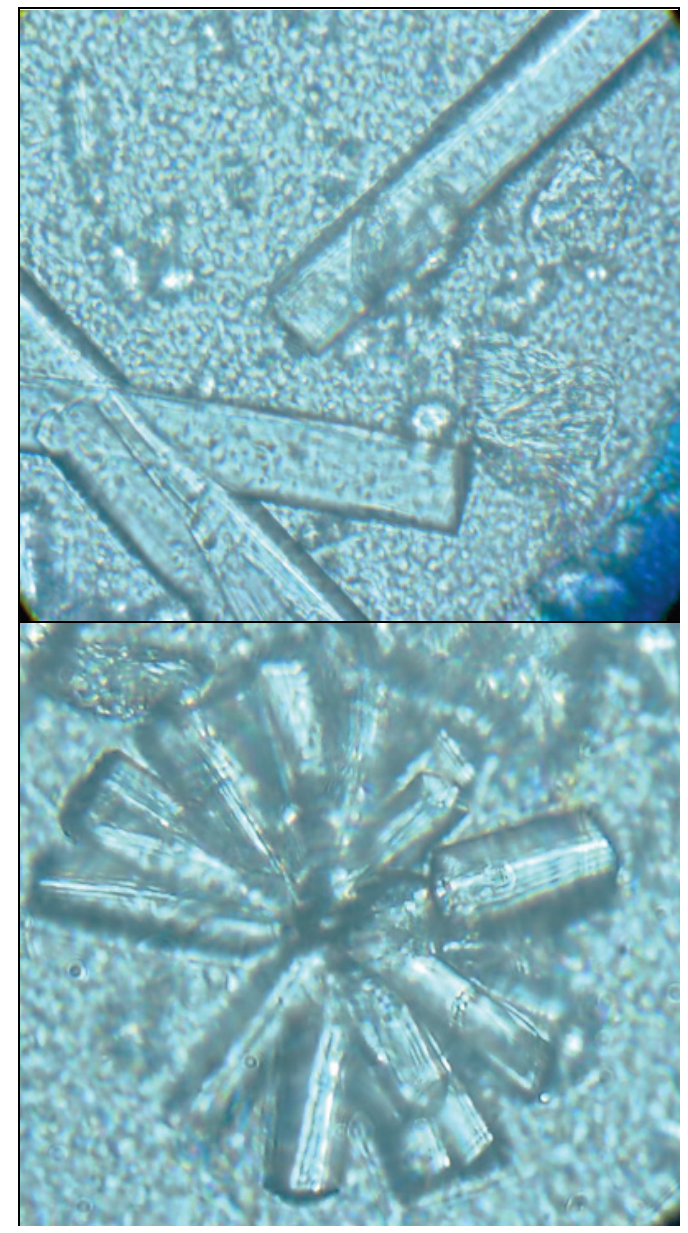

Fig. 2. $9 \alpha-\mathrm{OH}-\mathrm{AD}$ crystals in a culture broth $\mathrm{AD}$ transformation into $9 \alpha-\mathrm{OH}-\mathrm{AD}$ at a substrate load of $30 \mathrm{~g} / \mathrm{l}$

The $\mathrm{AD}$ transformation at a load of $30 \mathrm{~g} / \mathrm{L}$ was carried out under conditions selected in the previous experiments. To improve the biotrans- 
formation process, an additional portion of a concentrated inoculum and a glucose solution ( $5 \mathrm{~g} / 1)$ were added during the process (Fig. 3).

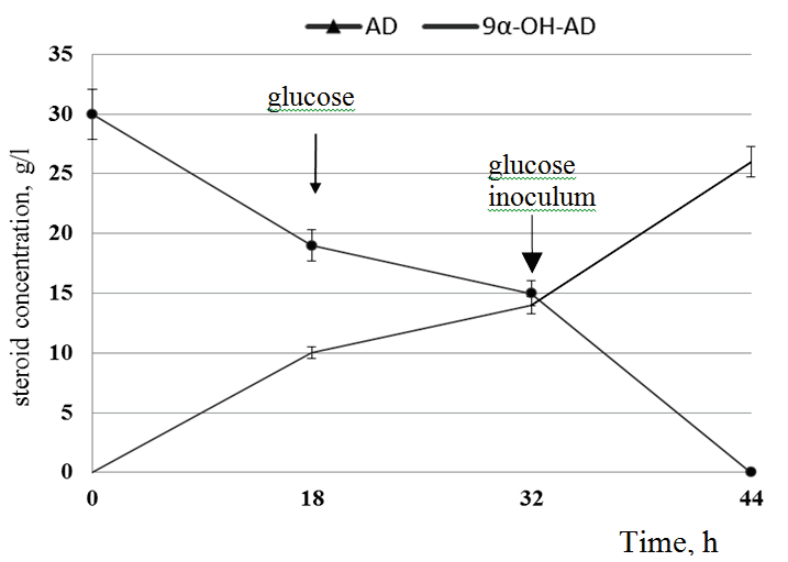

Fig. 3. Dynamics of $9 \alpha-O H-A D$ accumulation at the AD load of $30 \mathrm{~g} / \mathrm{l}$

According to this experiment, the substrate was completely transformed into $9 \alpha$-hydroxyproduct within $44 \mathrm{~h}$ of incubation. The yield of a technical $9 \alpha-\mathrm{OH}-\mathrm{AD}$ substance reached $83 \%$, while its content determined by HPLC was $93.6 \%$.

\section{Discussion}

According to many authors, nutrient medium composition influences the direction of the steroid reaction and on the rates of consumption of the initial substrate and accumulation of the target product. For example, changes in the concentration or the origin of organic nitrogen in a nutrient medium directly affect the biomass accumulation rate and can change the hydroxylating activity of cells. It was shown that the use of non-dehydrated nitrogen sources, such as casein, gelatin, and meat extract, provided a biomass possessing the higher transformational activity (Angelova et al., 1995). Soybean flour contains fatty acids, which positively influence the permeability of a bacterial cell wall and improve the availability of lipophilic substrates, such as steroid compounds, for enzymes of steroid-transforming microorganisms. Soybean flour also contains lecithin, a natural emulsifier preventing aggregation of steroid particles.

The results obtained in our study revealed no correlation between the biotransformation ability of Rh. erythropolis VKPM AC-1740 and the nitrogen source. The effect of a carbon source on the yield of a target $9 \alpha-\mathrm{OH}-\mathrm{AD}$ was more significant. We showed that the absence of glucose (preferred carbon source) in the medium resulted in a decreased $9 \alpha$ hydroxylation rate as compared with the glucose-containing medium (Table 1). We also observed the inhibition of a $9 \alpha$-hydroxylase activity in the media containing lactose or fructose as a carbon source. Our results agree with the data obtained by Angelova et al. (1995), who also showed the maximum biomass accumulation and a high substrate conversion rate in a glucose-containing medium.

A high hydrophobic property of steroid substrates in aqueous media results in a low degree of conversion of the initial substrate and a low yield of the target reaction product. Traditional approaches to reducing mass transfer limitations include the use of a fine-grain substrate and various surfactants or solvents able to mix with water, such as dimethyl sulfoxide, DMF, methanol, acetone, and 1,2-propanediol. To prevent deactivation of the biocatalyst, the amount of the added solvent usually does not exceed 1.5-5.0\% (v/v) (Fernandes et al., 2003). In addition, it is known that solvents may provide different effects, such as changes in the rate and direction of hydroxylation, as well as the stimulation or suppression of the by-product formation. According to some authors, microorganisms can include some solvents into their metabolic pathways to regenerate reduced cofactors (Angelova et al., 1995). Avramova et al. (2010) showed that the presence of Tween 80 in a glucose-containing medium accelerated the process of the $9 \alpha$-hydroxylation of AD.

In this study we showed that the surfactant presence in the nutrient medium during the $\mathrm{AD}$ transformation at a load within $5 \mathrm{~g} / \mathrm{l}$ did not result in an expected increase in the $9 \alpha-\mathrm{OH}-\mathrm{AD}$ generation rate as com- pared to the control (Table 2). A probable reason is that the strain itself may be able to emulsify and degrade hydrophobic substrates. According to the existing publications, such ability is determined mainly by specific structural features of the cell membrane of this microorganism, which is lipophilic, i.e., has a high affinity to hydrophobic substrates (Tsitko et al., 1999). The surface activity and hydrophobic character of the cell membrane promote interaction between the cells and insoluble substrate, which makes it possible to overcome a limited diffusion during the substrate uptake into a cell (Kostina, 2008). In addition, the composition of soybean flour includes lecithin, a natural emulsifier preventing aggregation of steroid particles (Petrusma et al., 2009; 2011; Jakočiunas et al., 2016; Liu et al., 2016). It is known that $\Delta 1$-2-dehydrogenation and $9 \alpha$-hydroxylation reactions resulting in the opening of the B ring of the steroid structure are the key reactions in the process of steroid utilization as carbon sources (Marques et al., 2010; Wilbrink et al., 2011; Brzezinska et al., 2013; Yeh et al., 2014). Data shown in Table 3 allow us to assume that the induction of the $9 \alpha-\mathrm{KSH}$ synthesis resulted in the induction of 1,2-dehydrogenase, responsible for the next reaction in steroid nucleus degradation pathway. This hypothesis may provide an explanation of the observed active $9 \alpha-\mathrm{OH}-\mathrm{AD}$ destruction. A possible reason for the lack of any undesirable $9 \alpha-\mathrm{OH}-\mathrm{AD}$ degradation (which was observed at the $\mathrm{AD}$ load of $5 \mathrm{~g} / \mathrm{l}$ ) during the $\mathrm{AD}$ transformation at a load of $10 \mathrm{~g} / \mathrm{l}$ is that the increased $\mathrm{AD}$ load resulted in the accumulation of $9 \alpha-\mathrm{OH}-\mathrm{AD}$ in the culture broth in the form of crystal-like structures (Fig. 3) unavailable for the further microbial destruction (Rodina et al., 2009). During this study we selected optimal conditions providing $\mathrm{AD}$ transformation at a load of $30 \mathrm{~g} / \mathrm{L}$ and obtaining a high output of a technical product. Our results suggest that further work is needed on the nutrient medium optimization and study of the effect of optimized media on the $9 \alpha-\mathrm{KSH}$ activity of $R$. erythropolis VKPM AC-1740 to provide the further increase of the $\mathrm{AD}$ load and to obtain a high yield of $9 \alpha-\mathrm{OH}-\mathrm{AD}$.

An obvious advantage of the proposed technology is acceleration of the transformation process due to a high substrate availability and use of a concentrated biomass that makes it possible to transform $\mathrm{AD}$ under high loads and under non-sterile conditions.

\section{Conclusion}

Replacement of corn extract with yeast extract and soybean flour, as well as the choice of glucose as a carbon source provided reduction of the duration of transformation while still maintaining a high $9 \alpha-\mathrm{OH}-\mathrm{AD}$ yield. At the same time, the effect of surfactants and the effect of 9-KSHmediated induction of $R$. erythropolis VKPM AC-1740 were positive only if they were applied for transformation with an increased substrate load. A 44-h AD transformation at a load of $30 \mathrm{~g} / \mathrm{l}$ by R. erythropolis VKPM AC-1740 resulted in the production of $9 \alpha-\mathrm{OH}-\mathrm{AD}$ with the yield of $83.0 \%$; the content of the target compound determined by HPLC was $93.6 \%$.

This study was supported by the programme of the Presidium of the Russian Academy of Sciences "Development of new biotechnological methods for obtaining highly active fluorinated corticosteroids of anti-inflammatory and antiallergic action from phytosterols via $9 \alpha$-hydroxy-AD using biologically modified immobilized biocatalysts" (project 1201371077).

\section{References}

Akhrem, A. A., \& Titov, Y. A. (1970). Steroids and microorganisms. Nauka, Moscow (in Russian).

Andryushina, V. V, Stytsenko, T. S., Voishvillo, N. E., Iaderetz, V. V., \& Druzhinina, A. V. (2013). Effect of the steroid molecule structure on the direction of its hydroxylation by the fungus Curvularia lunata. Applied Biochemistry and Microbiology, 49(4), 382-390.

Angelova, B., Mutafov, S., Avramova, T., Dimova, I., \& Boyadjie, L. (1996). $9 \alpha-$ Hydroxylation of 4-androstene-3,17-dione by resting Rhodococcus sp. cells. Process Biochemistry, 31(2), 179-184.

Arnell, R., Johannisson, R., Lindholm, J., Fornstedt, T., Ersson, B., Ballagi, A., \& Caldwell, K. (2007). Biotechnological approach to the synthesis of 9alphahydroxylated steroids. Preparative Biochemistry and Biotechnology, 3, 309-321.

Avramova, T., Spassova, D., Mutafov S., Momchilova S., Boyadjieva, L. Damyanova, B., \& Angelova, B. (2010). Effect of Tween 80 on 9a-steroid 
hydroxylating activity and ultrastructural characteristics of Rhodococcus sp cells. World Journal of Microbiology and Biotechnology, 26, 1009-1014.

Barredo, J.-L., \& Herráiz, I. (Eds.). (2017). Microbial steroids: Methods and protocols. Methods in Molecular Biology. Springer Science + Business Media LLC, 1645, 373.

Bhatti, H. N., \& Khera, R. A. (2012). Biological transformations of steroidal compounds: A review. Steroids, 77, 1267-1290.

Brzezinska, M., Szulc, I., Brzostek, A., Klink, M., Kielbik, M., Sulowska, Z., Pawelczyk, J., \& Dziadek, J. (2013). The role of 3-ketosteroid 1(2)-dehydrogenase in the pathogenicity of Mycobacterium tuberculosis. BMC Microbiology, 13, 43 .

Carpova-Rodina, N. V., Andryushina, V. A., Yaderetz, V. V., Druzhinina, A. V., Stytsenko, T. S., Shaskol'skiy, B. L., Lozinsky, V. I., Huy Luu, D., \& Voishvillo, N. E. (2011). Transformation of $\Delta 4$-3-ketosteroids by free and immobilized cells of Rhodococcus erythropolis actinobacterium. Applied Biochemistry and Microbiology, 47(4), 386-392.

Donova, M. V. (2017). Steroid bioconversions. Methods in Molecular Biology, $1645,1-13$.

Egorova, O. V., Nikolayeva, V. M., Sukhodolskaya, G. V., \& Donova, M. V. (2009). Transformation of $\mathrm{C}_{19}$-steroids and testosterone production by steroltransforming strains of Mycobacterium sp. Journal of Molecular Catalazysis B: Enzymatic, 57, 198-203.

Fernández de las Heras, L., van der Geize, R., Drzyzga, O., Perera, J., \& NavarroLlorens, M. J. (2012). Molecular characterization of three 3-ketosteroid- $\Delta(1)$ dehydrogenase isoenzymes of Rhodococcus ruber strain Chol-4. Journal of Steroid Biochemistry and Molecular Biology, 132, 271-281.

Fernandez-Cabezon, L., Galán, B., \& García, J. L. (2018). New insights on steroid biotechnology. Frontiers in Microbiology, 9, 958.

Guevara, G., Fernández de las Heras, L., Perera, J., Navarro, M., \& Llorens, J. (2017b). Functional differentiation of 3-ketosteroid $\Delta$ 1-dehydrogenase isozymes in Rhodococcus ruber strain Chol-4. Microbial Cell Factories, 16(1), 42.

Guevara, G., Heras, L. F. L., Perera, J., \& Llorens, J. M. N. (2017a). Functional differentiation of 3-ketosteroid 9 $\alpha$-hydroxylases in Rhodococcus ruber strain Chol-4. Journal of Steroid Biochemistry and Molecular Biology, 7, 176-187.

Haußmann, U., Wolters, D. A., Fränzel, B., Eltis, L. D., \& Poetsch, A. (2013). Physiological adaptation of the Rhodococcus jostii RHA1 membrane proteome to steroids as growth substrates. Journal of Proteome Research, 12, 1188-1198.

Jakočiunas, T., Jensen, M. K., \& Keasling, J. D. (2016). CRISPR/Cas9 advances engineering of microbial cell factories. Metabolic Engineering, 34, 44-59.

Knol, J., Bodewits, K., Hessels, G. I., Dijkhuizen, L., \& van der Geize, R. (2008). 3-Keto-5alpha-steroid delta(1)-dehydrogenase from Rhodococcus erythropolis SQ1 and its orthologue in Mycobacterium tuberculosis H37Rv are highly specific enzymes that function in cholesterol catabolism. Biochemistry Journal, 410, 339-346.

Lee, J. Y., Na, Y. A., Kim, E., Lee, H. S., \& Kim, P. (2016). The actinobacterium Corynebacterium glutamicum, an industrial workhorse. Journal of Microbiology and Biotechnology, 26, 807-822.

Li, H., Sun, J., \& Xu, Z. (2017). Biotransformation of DHEA into $7 \alpha, 15 \alpha$-diOHDHEA. Methods in Molecular Biology, 1645, 289-295.

Liu, Y., Shen, Y., Qiao, Y., Su, L., Li, C., \& Wang, M. (2016). The effect of $3-$ ketosteroid- $\Delta(1)$-dehydrogenase isoenzymes on the transformation of $\mathrm{AD}$ to $9 \alpha-\mathrm{OH}-\mathrm{AD}$ by Rhodococcus rhodochrous DSM 43269. Journal of Industrial Microbiology and Biotechnology, 43, 1303-1311.

Marques, M. P. C., Carvalho, F., de Carvalho, C. C. C. R., Cabral, J. M. S., \& Fernandes, P. (2010). Steroid bioconversion: Toward green processes. Food and Bioproduct Processing, 88, 12-20.

Mashkovskiy, M. D. (2012). Medicinal products. New Wave, Moscow (in Russian).

Mohn, W. W., Wilbrink, M. H., Casabon, I., Stewart, G. R., Liu, J., van der Geize, R., \& Eltis, L. D. (2012). Gene cluster encoding cholate catabolism in Rhodococcus spp. Journal of Bacteriology, 194, 6712-6719.
Mondaca, M. A., Vidal, M., Chamorro, S., \& Vidal, G. (2017). Selection of biodegrading phytosterol strains. Methods in Molecular Biology, 1645, 143-150.

Murphy, K. C., Papavinasasundaram, K., \& Sassetti, C. M. (2015). Mycobacterial recombineering. Methods in Molecular Biology, 1285, 177-199.

Mutafova, B., Mutafov, S., Fernandes, P., \& Berkov, S. (2016). Microbial transformations of plant origin compounds as a step in preparation of highly valuable pharmaceuticals. Journal of Drug Metabolism and Toxicology, 7(2), 1-11.

Nielsen, J., \& Keasling, J. D. (2016). Engineering cellular metabolism. Cell, 164, 1185-1197.

Petrusma, M., Dijkhuizen, L., \& van der Geize, R. (2009). Rhodococcus rhodochrous DSM 43269 3-ketosteroid 9alpha-hydroxylase, a two-component iron-sulfur-containing monooxygenase with subtle steroid substrate specificity. Applied and Environmental Microbiology, 75, 5300-5307.

Petrusma, M., Hessels, G., Dijkhuizen, L., \& van der Geize, R. (2011). Multiplicity of 3-ketosteroid-9 $\alpha$-hydroxylase enzymes in Rhodococcus rhodochrous DSM 43269 for specific degradation of different classes of steroids. Journal of Bacteriology, 193, 3931-3940.

Petrusma, M., van der Geize, R., \& Dijkhuizen, L. (2014). 3-Ketosteroid 9a-hydroxylase enzymes: Rieske non-heme monooxygenases essential for bacterial steroid degradation. Antonie van Leeuwenhoek, 106, 157-172.

Ribeiro, A. L., Sánchez, M., Hidalgo, A., \& Berenguer, J. (2017). Stabilization of enzymes by using thermophiles. Methods in Molecular Biology, 1645, 297-312.

Rodina, N. V., Andryushina, V. V, Stytsenko, T. S., Turova, T. P., Baslerov, R. V., Panteleeva, A. N., \& Voishvillo, N. E. (2009). The introduction of the $9 \alpha-$ hydroxy group into androst-4-en-3,17-dione using a new actinobacterium strain. Applied Biochemistry and Microbiology, 45(4), 395-400.

Smitha, M. S., Singh, S., \& Singh, R. (2017). Microbial biotransformation: A process for chemical alterations. Journal of Bacteriology and Mycology, 4(2), 85.

Tsitko, I. V., Zaitsev, G. M., \& Lobanok, A. G. (1999). Effect of aromatic compounds on cellular fatty acid composition of Rhodococcus opacus. Applied and Environmental Microbiology, 65(2), 853-855.

van der Geize, R., Hessels, G. I., Nienhuis-Kuiper, M., \& Dijkhuizen, L. (2008) Characterization of a second Rhodococcus erythropolis SQ1 3-ketosteroid 9alpha-hydroxylase activity comprising a terminal oxygenase homologue, KshA2, active with oxygenase-reductase component KshB. Applied and Environmental Microbiology, 74, 7197-7203.

van der Geize, R., Hessels, G. I., van Gerwen, R., van der Meijden, P., \& Dijkhuizen, L. (2001). Unmarked gene deletion mutagenesis of kstD, encoding 3-ketosteroid delta1-dehydrogenase, in Rhodococcus erythropolis SQ1 using sacB as counter-selectable marker. FEMS Microbiological Letters, 205, 197-202.

van der Geize, R., Hessels, G. I., van Gerwen, R., Vrijbloed, J. W., van Der Meijden, P., \& Dijkhuizen, L. (2000). Targeted disruption of the kstD gene encoding a 3-kestosteroid $\Delta(1)$-dehydrogenase isoenzyme of Rhodococcus erythropolis strain SQ1. Applied and Environmental Microbiology, 66, 2029-2036.

Voishvillo, N. E., Rodina, N. V., Andrjushina, V. A., Stytsenko, T. S., \& Skryabin, K. G. (2007). Strain Rhodococcus erythropolis VKPM Ac-1740 for 9alphahydroxysteroids. Patent RU 2351645 (in Russian).

Wei, J. H., Yin, X., \& Welander, P. V. (2016). Sterol synthesis in diverse bacteria. Frontiers in Microbiology, 7, 990.

Wilbrink, M. H., Petrusma, M., Dijkhuizen, L., \& van der Geize, R. (2011). FadD19 of Rhodococcus rhodochrous DSM 43269, a steroid-coenzyme. A ligase essential for degradation of C-24 branched sterol side chains. Applied and Environmental Microbiology, 77, 4455- 4464.

Yeh, C. H., Kuo, Y. S., Chang, C. M., Liu, W. H., Sheu, M. L., \& Meng, M. (2014). Deletion of the gene encoding the reductase component of 3-ketosteroid $9 \alpha$-hydroxylase in Rhodococcus equi USA-18 disrupts sterol catabolism, leading to the accumulation of 3-oxo-23,24-bisnorchola-1,4-dien-22-oic acid and 1,4-androstadiene-3,17-dione. Microbial Cell Factories, 13, 130. 